\title{
NUMERICAL INVESTIGATION OF INITIAL CONDITIONS INFLUENCE ON THE VALUE OF PRESSURE IMPULSE ACTING ON SPECIAL VEHICLE DURING ACCEPTANCE TESTING
}

\author{
Wiesław Barnat ${ }^{1}$ \\ 1 Departament of Mechanics and Applied Computer Science, Military University of Technology, ul. Gen. S. \\ Kaliskiego 2, 00-908 Warszawa, e-mail: wieslaw.barnat@wat.edu.pl
}

Received: 2017.04.05

Accepted: 2017.05.02

Published: 2017.06.01

\begin{abstract}
The article presents the results of works aiming at comparing a methodology of research on the effect of a pressure impulse coming from detonation of trinitrotoluene TNT. Within the work, the influence of the explosive material detonation environment on the pressure impulse was studied. The analysis was carried out with Finite Element Method (FEM). Two cases of mine detonation in the sparse ground (sand) and explosive charge detonation in the tested model of a mine were selected. The model was described in the currently applied standardization regulations utilized for military and exploitation acceptance of special equipment.
\end{abstract}

Keywords: acceptance testing of the equipment, explosion, ground, mine model.

\section{INTRODUCTION}

Special vehicles are structures designed, first of all, as mechanical vehicles for transportation of soldiers, special equipment and supplies. Another condition to be satisfied by such vehicles is impact resistance to any kinds of dynamic loads resulting from fast driving [5] or explosion [1, 10]. Such structures are exposed to effects of many firing assets possessed by the enemy, including mainly Improvised Explosive Devices - IED. Due to the structure irregularity of the above mentioned assets, there is a high probability of designing such a vehicle which is supposed to satisfy the relevant standards of protection [1, 10]; however it will not protect the vehicle crew against the explosion of IED.

Designers examining the documents describing the operational requirements of a vehicle are aware that these vehicles are exposed to mines, particularly armour-piercing ones. Given a mass of an armour-piercing mine, namely a TNT charge mounted in it, there is a high probability of determining a value of a pressure impulse acting on the vehicle during acceptance testing.
Another important problem for the committee accepting the vehicle is a manner of explosive charge initiation and environment in which the charge was placed. The advertising folders presenting that a given vehicle withstands an explosion of $10 \mathrm{~kg}$ of TNT are widely known. One of the basic question asked by the committee member should be about the conditions in which the charge was placed. The article presents the influence of the detonation environment of a charge utilised during testing of special vehicle on the value of the pressure impulse.

\section{DESCRIPTION OF THE ANALYZED MODELS OF EXPLOSION}

One of the fundamental problems in modelling the phenomenon of blast wave propagation is a description of the detonation phenomenon and a manner of interaction between explosive material and the environment of explosion propagation [2, $5,7,8]$. A problem of blast wave impulse propagation quite significant in terms of the response of an explosion-vehicle-human being system. 


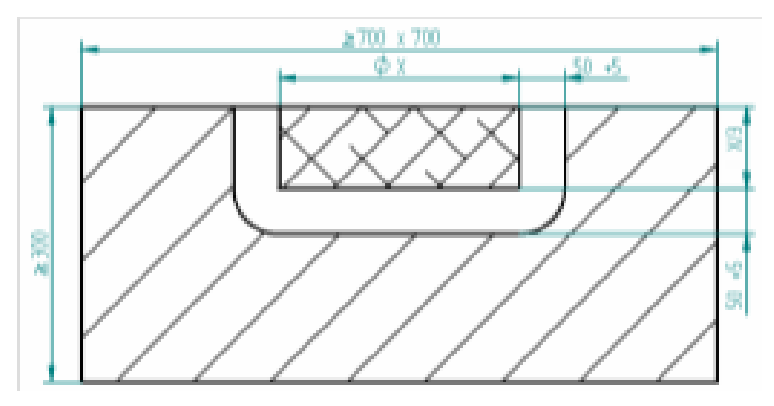

Fig. 1. Diagram of a mine [10]

It is really important to determine the force acting on a human being, in fact the duration of a force impulse, during an explosion. This force is dependent on the environment in which the explosive material was placed. For the case of an explosion in the ground, there are many works describing the dependency between the size of an explosive charge and the size of an explosion crater. An influence of the ground type, in which detonation occurs, is difficult to estimate. Due to a considerable non-homogeneity and discontinuity of the medium (ground) [3,6] during tests and acceptance testing, the acceptance testing of the vehicles loaded by an explosive charge in the ground is abandoned. NATO adopted standardization regulations which allow for blowing up the vehicles loaded by an explosive charge placed in a properly prepared ground. The most significant impediment to such a process is a proper preparation of the ground which should be characterized by a proper density and dampness. Additionally, dimensions of the region of a properly prepared ground are essential.

To avoid tedious preparations of the ground, a simplified model of an anti-piercing mine was developed by NATO.

A manner of placing an igniter (initiating an explosion) is crucial during acceptance testing. According to the regulations in force, an igniter should be placed at the maximum depth of 0.33 of the explosive charge height. Table 1 presents dimensions characteristic for particular masses of anti-piercing mines.

A numerical model of mine explosion developed based on geometry described in STANAG 4569 was applied to numerical analyses of research on a characteristic of the environment utilized for testing. In the case of mine placed in the ground, a ground description with the use of Euler's domain with relevant constitutive parameters was applied. The explosive material was
Table 1. Characteristic dimensions of TNT charge for particular masses of mines [10]

\begin{tabular}{|c|c|c|}
\hline TNT mass & D & H \\
\hline$[\mathrm{kg}]$ & {$[\mathrm{mm}]$} & {$[\mathrm{mm}]$} \\
\hline 6 & 250 & 80 \\
\hline 8 & 270 & 90 \\
\hline 10 & 290 & 97 \\
\hline
\end{tabular}

described with Jones-Wilkins-Lee (JWL) constitutive model. In the model, the main parameters of the explosive material were described. Additionally, to describe the explosion more precisely, a point of an explosive material detonation, consistent with STANAG 4569, was indicated. To estimate the obtained results, Euler cell located at a distance of $0.4 \mathrm{~m}$ from the mine was chosen. This distance is equal to an average clearance of the special vehicle. The value of pressure (casual wave), velocity and total energy of the medium was read in this cell. This value is important due to estimation of damping parameters utilized in protective seats.

All the comparative figures were prepared for the same moments of time.

To model Euler domain, cubic elements were used. Such a selection of a shape results from a necessity to adjust the elements of the Euler mesh to the mesh of Lagrange elements defining the tested object. A spherical blast wave propagating in a mesh of cubic elements undergoes deformation compared to the results of pressure wave simulation for a mesh mapping the shape of sphere. The shape of the blast wave in the latter case is more regular.

A scheme of equal integration of the equations in time was applied for calculations.

\section{THE RESULTS OF NUMERICAL ANALYSE}

Numerical analysis was conducted for models presented in Figure 2. The models included the following Euler areas: air, explosive charge, ground. Two cases of both the ground and the test model of an anti-piercing mine were considered in the numerical analysis.

The pressure wave induced by detonation propagated in the cube-shape area with the given relevant boundary conditions. Additionally, the point of explosive charge initiation was determined. Symmetries of system a were declared on the symmetry planes, whereas, pressure condition 


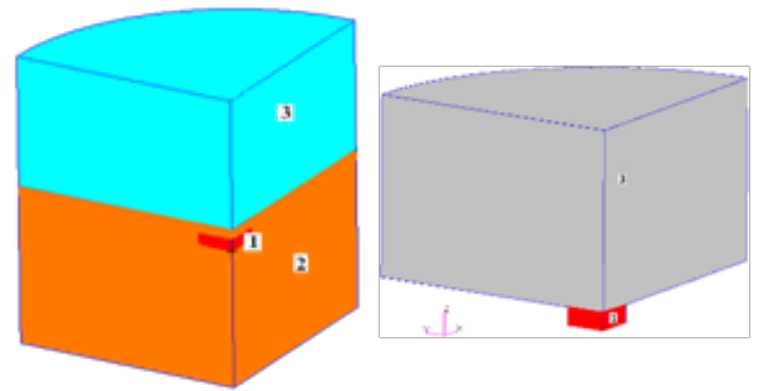

Fig. 2. Scheme of the numerical model. 1 - explosive charge, 2 - ground, 3 - air

of flow was declared for the free planes. For the mine model, according to STANAG, the relevant flows were declared to the planes in which limitations caused by the mine occurred.

A theoretical solution of pressure impulse propagation in the form of a strong discontinuity of a spherical shape, originated from a point source, allows for a computer simulation of pressure wave propagation through giving relevant initial conditions (density, energy, pressure) to certain selected elements from Euler domain. Next, solution of mass, momentum and energy conservation laws is carried out. Typical values of physical properties for explosive materials are: density $-1600 \mathrm{~kg} / \mathrm{m}^{3}$ and specific internal energy $-4.2 \mathrm{MJ} / \mathrm{kg}[2,4]$.

The air, in which the blast wave propagated, was modelled with Euler elements of Hex 8 type characterized with properties of ideal gas with $\gamma=1.4$ density corresponding to density of atmospheric air in normal conditions $(\rho=1.2829 \mathrm{~kg}$ / $\mathrm{m} 3$ ). The ground was described with Mie-Gruneisen $[6,9]$ material model with the following parameters: $\gamma=2$ and density corresponding to the density of the relevant type of ground. The model of the test mine was described with a relevant initial-boundary conditions. The ground model was validated based on the available literature and on previous works.

As a result of numerical analysis, distributions of the pressure and density of the medium in which the pressure wave propagated were obtained. For the first case of numerical analysis, i.e., explosion in the ground, the analysis of explosion was carried out in the sparse ground. Such a ground type is common on testing fields in Poland. The averaged material data were adopted for numerical analyses.

Due to considerable discrepancies for particular types of ground, the analysis was conducted for the average values of coefficients describing the ground. The results for the particular moments are presented for the figures below. A description of the results was combined for the analysed cases in order to obtain clear and easy estimation of the results.

A description of the obtained results was presented as distributions of pressure, velocity of the medium and its density for two moments of time: the moment when a pressure impulse reaches the vehicle bottom $\mathrm{t}=0.0001 \mathrm{~s}$ and the final moment, i.e., a decrease (stabilization) of the pressure impulse $\mathrm{t}=0.001 \mathrm{~s}$.

During initiation of the explosion in the charge - detonation, the pressure values were similar. Due to a difference in defining the conditions limiting the explosion, there is a significant difference for a pressure value for time $0.0001 \mathrm{~s} \mathrm{(Fig.} \mathrm{3).} \mathrm{A} \mathrm{pres-}$ sure value for the sparse ground (Fig. 3a) for the explosion epicentre was $5.33 \mathrm{E} 8 \mathrm{~Pa}$, whereas in the point close to a vehicle bottom it was $4.5 \mathrm{E} 7 \mathrm{~Pa}$ a)

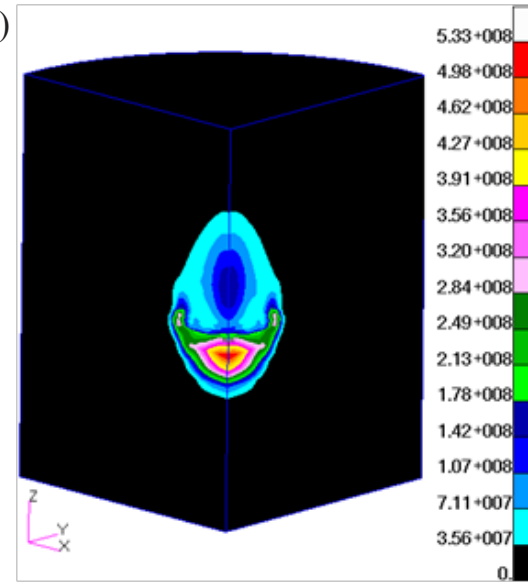

b)

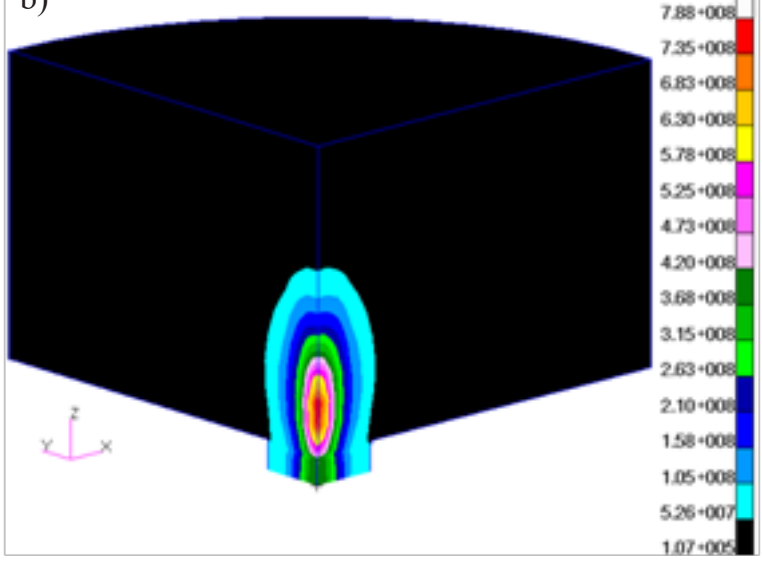

Fig. 3. Distribution of pressure for time $t=0.0001 \mathrm{~s}$ 


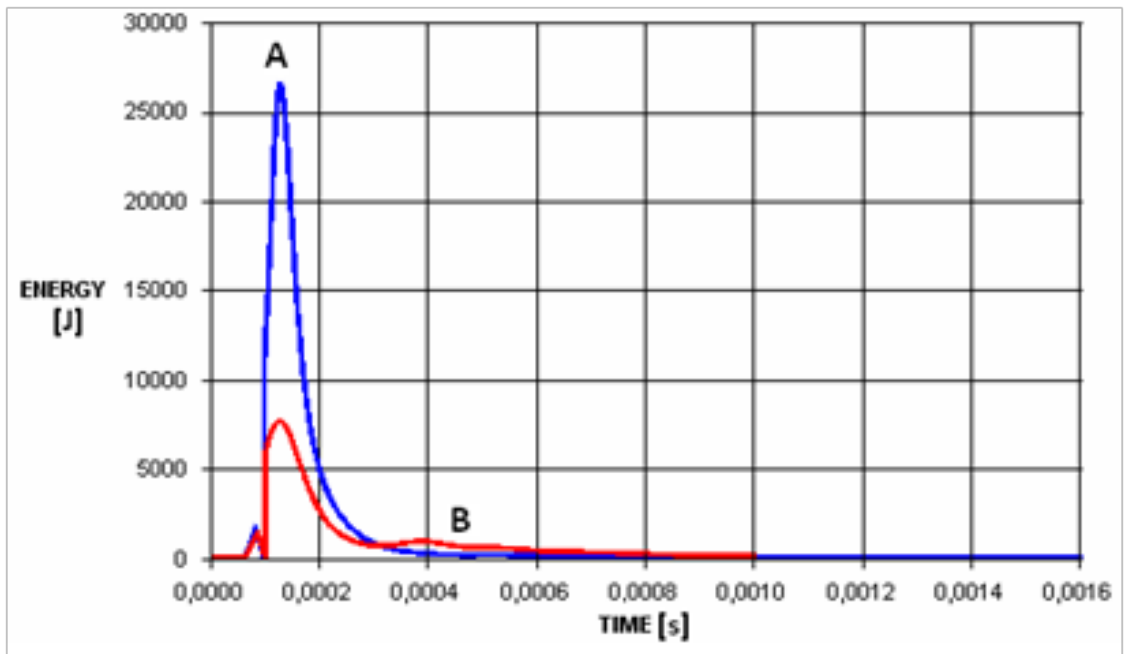

Fig. 4. A graph of pressure change for the considered cases

(A- STANAG - mine model, B - explosion of a mine in the ground)

a)

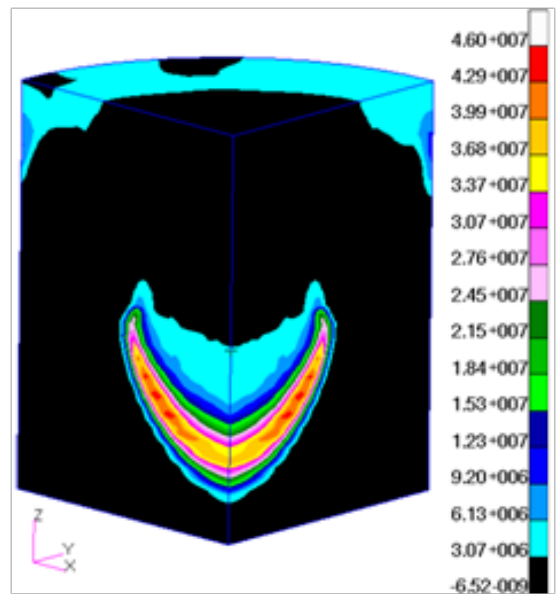

b)

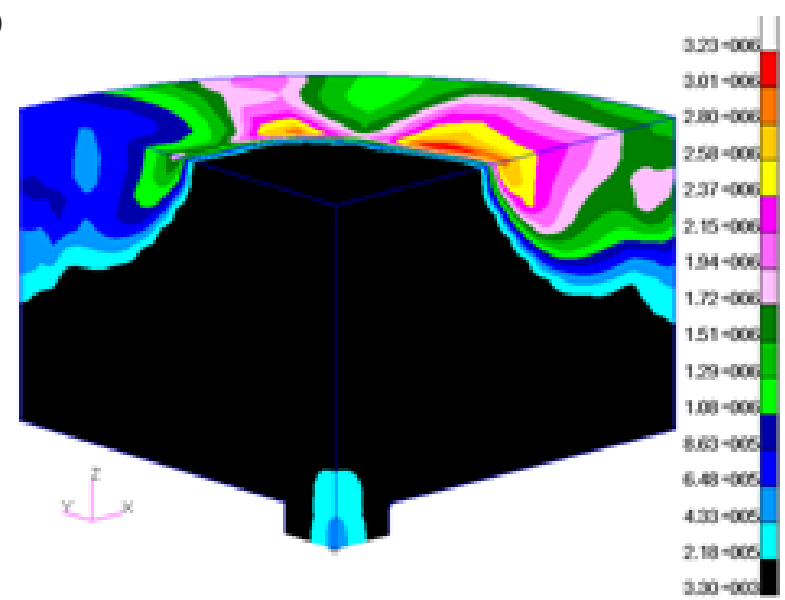

Fig. 5. Distribution of pressure for time $t=0.001 \mathrm{~s}$

(Fig. 4). The explosive charge placed in the mine model behaved in quite different way.

Pressure values for the mine test model (Fig. $3 b)$ for the explosion epicentre was almost twice as high and it was equal to $7.88 \mathrm{E} 8 \mathrm{~Pa}$, whereas in the point close to the vehicle bottom, the difference was four times as much higher and was equal to 1.7E8 Pa (Fig. 4).

After stabilization of the pressure impulse, the tested cases behave similarly for time 0.0001 s. A difference in pressure for the case of explosion in the ground and for the mine model is very important. In the first case (Fig. 5a), an increase in the pressure value was recorded for the medium with the increased density, i.e., the ground. In the case of explosion in the mine model (according to STANAG), an increased value of pressure was recorded for the area of the mine in which detonation propagated (Fig. $5 b)$. Such an increase in pressure in this area resulted from multiple wave reflection from the mine model walls.

During initiation of explosion in the charge detonation - similarly as in the case of pressure, the velocity values of a gas medium were close. Due to a difference in definition of conditions limiting the explosion, there is a clear difference for the values of velocity for time 0.0001 (Fig. 6 ). The velocity values for the sparse ground (Fig. 6a) for the explosion epicentre was 3120 $\mathrm{m} / \mathrm{s}$, whereas in the point close to the vehicle bottom it was $2800 \mathrm{~m} / \mathrm{s}$ (Fig. 7). The value of velocity for the test model of a mine (Fig. 6b) for the explosion epicentre was higher $-3470 \mathrm{~m} / \mathrm{s}$, whereas in the point close to the vehicle bottom $-3000 \mathrm{~m} / \mathrm{s}$ (Fig. 6b). 
a)

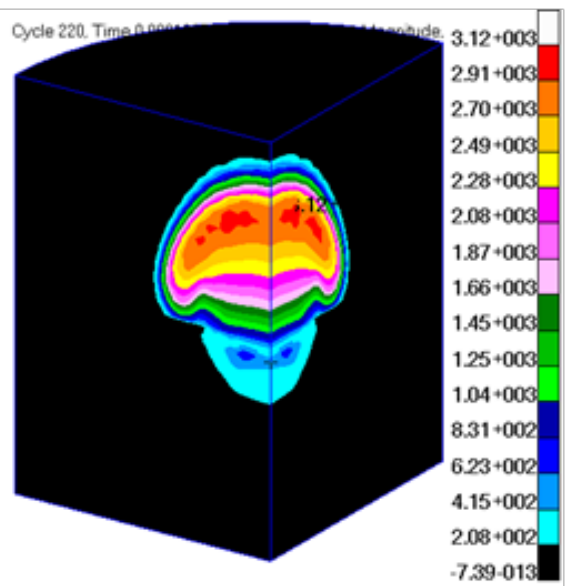

b)

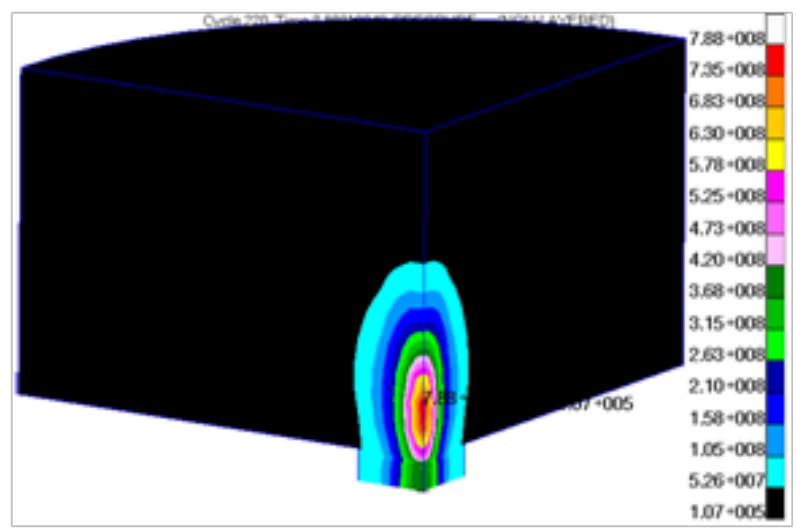

Fig. 6. Distribution of velocity for time $t=0.0001 \mathrm{~s}$

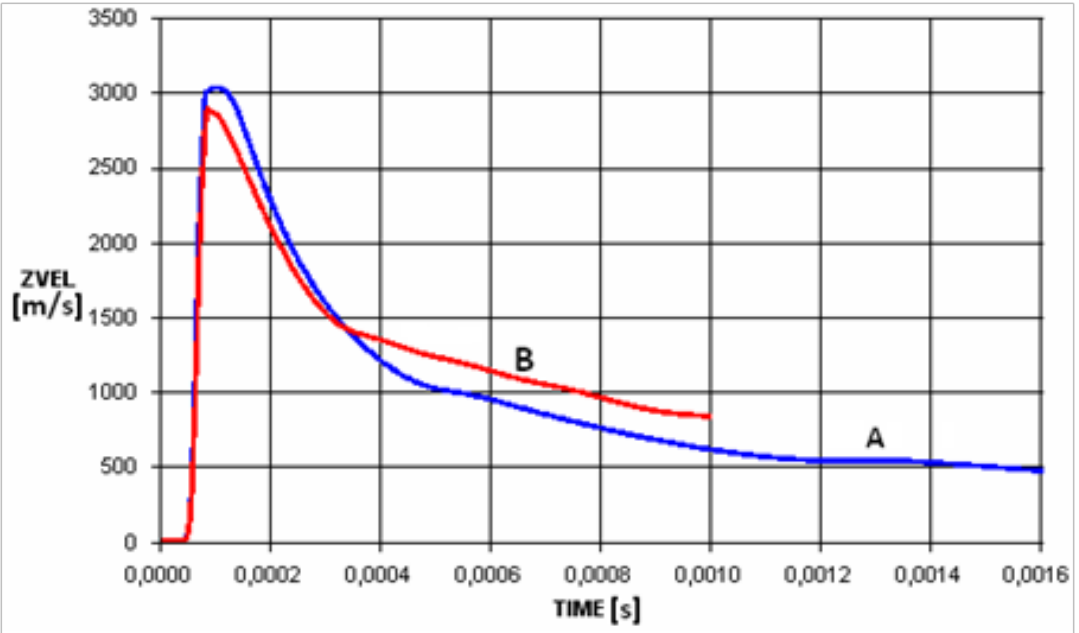

Fig. 7. A graph of velocity change for the considered cases

(A-STANAG - mine model, B - explosion of a mine in the ground)

a)

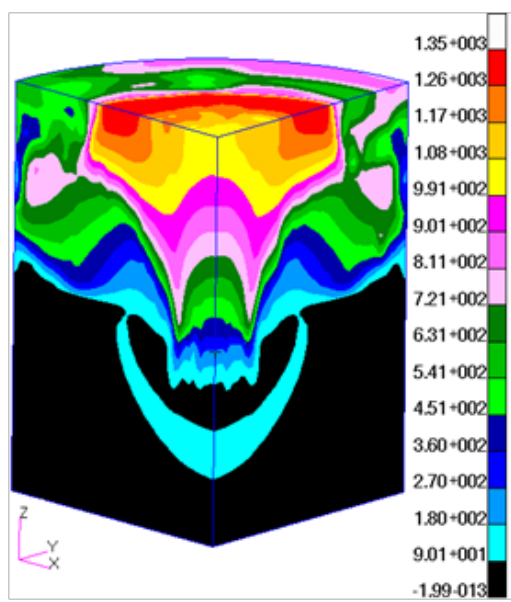

b)

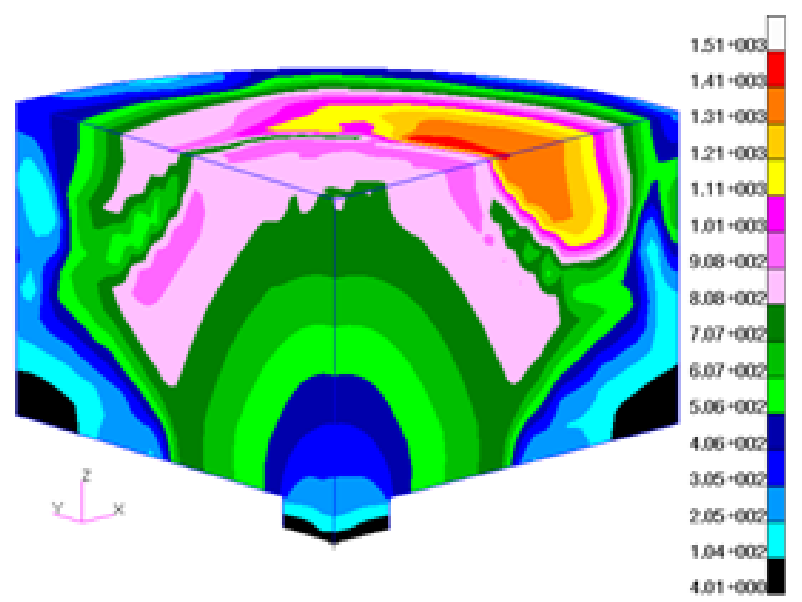

Fig. 8. Distribution of velocity for time $t=0.001 \mathrm{~s}$

The course of pressure velocities for the considered cases in the point close to the vehicle bottom is presented in Fig. 7.
After stabilization of the impulse, the cases tested in terms of velocity behave similarly (for time $0.0001 \mathrm{~s}$ ). A difference in velocity for the 
ground and for the mine model is very important. In the first case (Fig. 8a), an increase in velocity was recorded for the medium with the increased density, i.e., the ground. In the case of the mine model, an increased value of pressure was recorded for the area of the mine in which detonation propagated (Fig. 8b). Such an increase in velocity in this area resulted from multiple wave reflection from the mine model walls.

During initiation of explosion in the charge - detonation - similarly as in the case of pressure, the density values of a gas medium were close. Due to a difference in definition of conditions limiting the explosion, there is a clear difference for the values of density for time 0.0001 (Fig. 9). The density value for the sparse ground (Fig. 9a) is the highest and results from ground densification by the explosion and was equal to $5090 \mathrm{~kg} / \mathrm{m}^{3}$, whereas in the point close to the vehicle bottom it was 60 $\mathrm{kg} / \mathrm{m}^{3}$ (Fig. 10). The charge placed in the stiff model of a mine behaved differently.

The density value for the tested model of the mine (Fig. 9b) for the explosion epicentre was significantly higher and was equal to 5720 $\mathrm{kg} / \mathrm{m}^{3}$, whereas in the point close to the vehicle bottom, the value of medium density was significantly lower $-178 \mathrm{~kg} / \mathrm{m}^{3}$ (Fig. 10). Such a value from the occurrence of detonation products mixed with the air.

After stabilization of the pressure impulse, the tested cases behave similarly (for time $0.0001 \mathrm{~s}$ ). A difference in density for the ground and for the mine model is very important. In the first case (Fig. 11a), an increase in velocity was recorded for the medium with the increased density, i.e., the ground. In the case of the mine, an increased value of pressure was recorded for the area of the mine in which a)

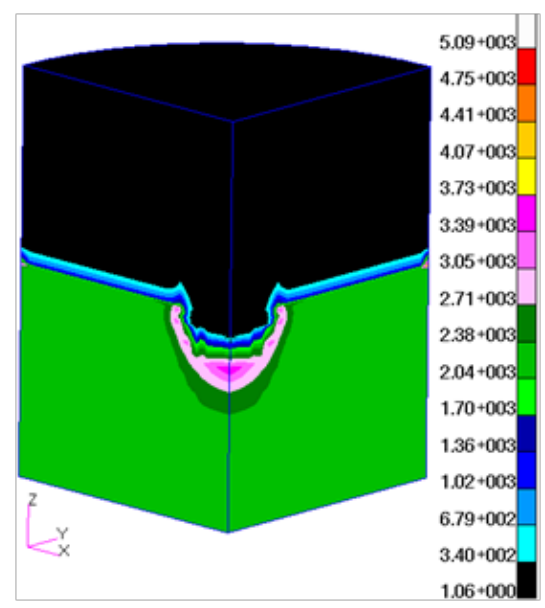

b)

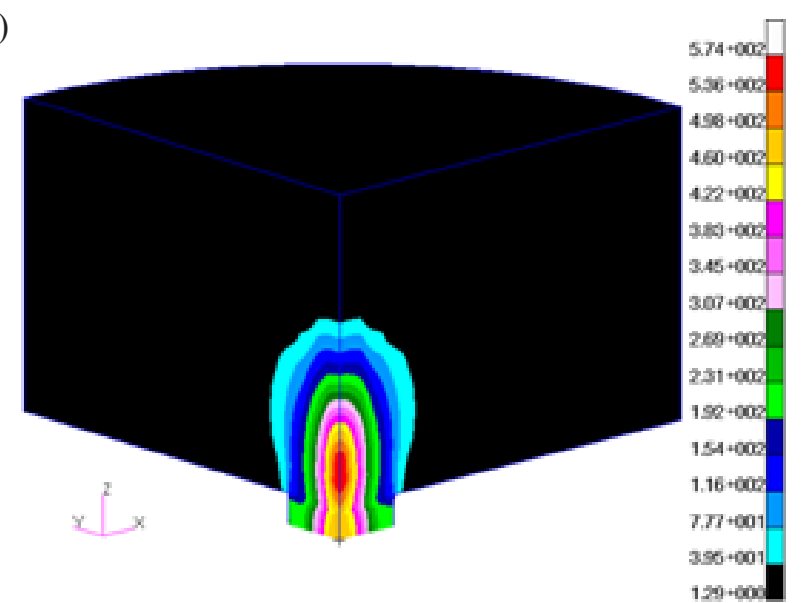

Fig. 9. Distribution of density for time $t=0.001 \mathrm{~s}$

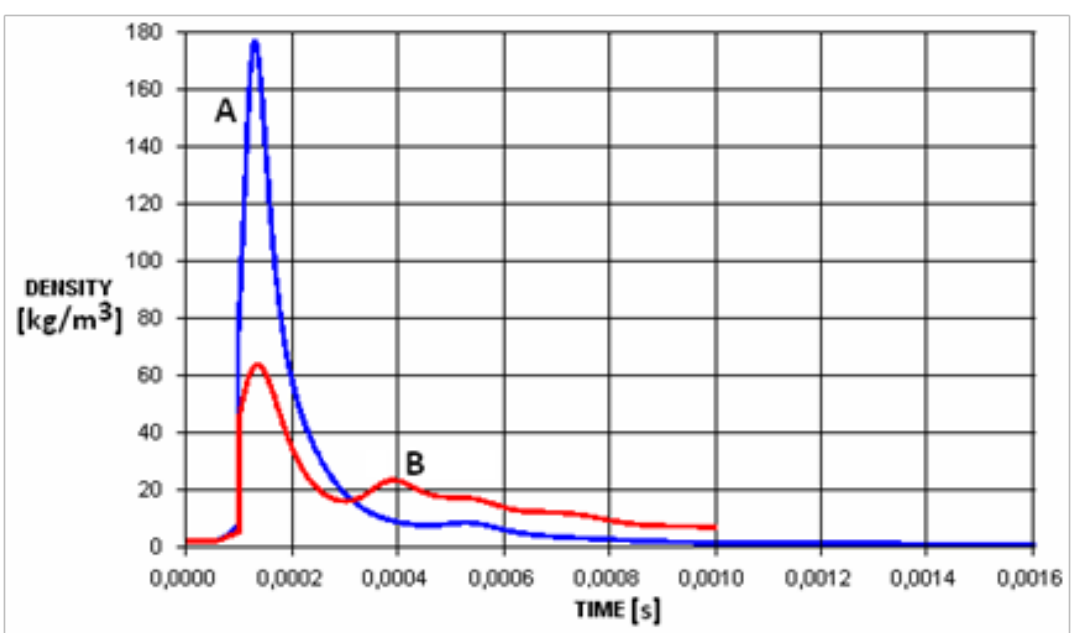

Fig. 10. A graph of density change for the considered cases (A-STANAG - mine model, B - explosion of a mine in the ground) 
a)

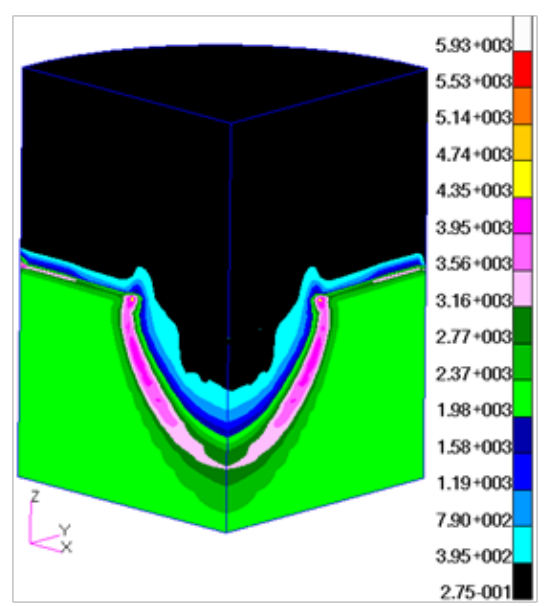

b)

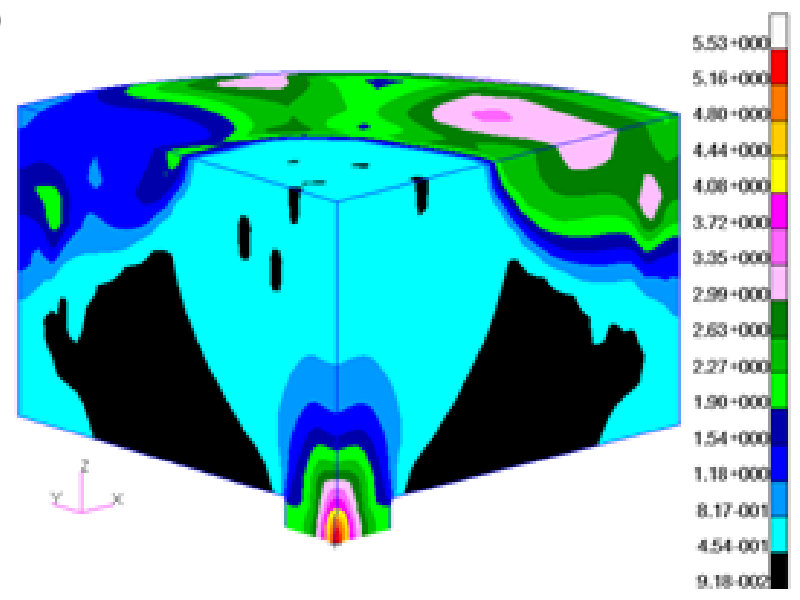

Fig. 11. Distribution of density for time $t=0.001 \mathrm{~s}$

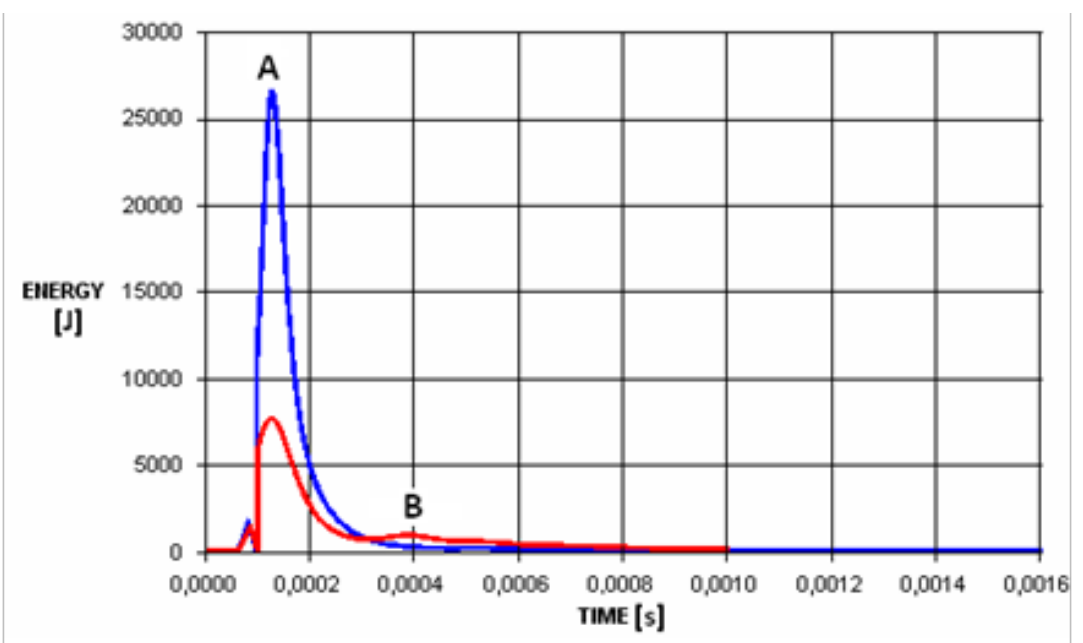

Fig. 12. A graph of energy change for the considered cases (A-STANAG - mine model, B - explosion of a mine in the ground)

detonation propagated (Fig. 11b). Such an increase in density in this area resulted from multiple wave reflection from the mine model walls as well as from detonation products mixed with the air.

Estimation of the results is more precise in the case of evaluation of the so called energy balance. A change in total energy of the system is presented in Figure 12. It should be noted that this energy is transmitted onto the loaded structure.

In the case of analysis of the mine model described in STANAG, the maximum value of energy in the area close to the vehicle bottom was $27 \mathrm{~kJ}$, whereas in the case of explosion in the ground $-7.5 \mathrm{~kJ}$.

A three and a half difference in energy is due to division of the energy acting on the structure. In the case of a mine model, according to STANAG, the entire energy is directed to the vehicle bot- tom. Placing the explosive charge in the ground results in the fact that a significant part of energy is directed to the ground.

\section{CONCLUSIONS}

The article presents the results of analysis of the environment influence on the value of pressure acting on the tested structure of a mechanical vehicle. Previous works did not include evaluation of an influence of the above mentioned factors.

Due to considerable differences in the parameters describing the ground, it is not possible to obtain in the natural environment the results approximate to the results for numerical and experimental tests. It is possible, owing to the validation process, to obtain the approximate results for numerical and experimental tests. As a results of the 
computer experiment, there were obtained significant differences in pressure values for explosion both in the ground and in the mine model according to STANAG. This phenomenon is interesting due to a value of energy coming from explosion of the same TNT charge on the tested structure.

Huge development of numerical methods as well as an increase in calculating capabilities of modern computers allow for modelling of many physical phenomena. The above mentioned development in connection with better and better care about passive protection of a vehicle crew results in searching for newer and newer construction solutions not only with the use of experimental methods, but also with a computer experiment.

Application of a finite element method for numerical analyses allows for considerable faster obtainment of the results. However, the obtained results should be approached with caution or even distrust. Application of not only pressure but also the values such as density, energy and energy of a medium to the description was a novelty presented in this article. These parameters present a full description of the results. Hitherto, authors neglected the above mentioned values in their articles.

\section{Acknowledgements}

The article was financed from project: NCBiR DOB-BiO/001/05/2014, New floating infantry combat vehicle.

\section{REFERENCES}

1. AEP-55 Procedures for evaluating the protection level of logistic and light armoured vehicle, Volume 2 for mine threat (Edition 2), NATO/PfP Unclassified publication, 2005.

2. Baker W. et al., Zjawiska Wybuchowe, Wydawnictwo Mir Moskwa, 1986.

3. Barnat W. Wybrane zagadnienia oddziaływania wybuchu min i improwizowanych urządzeń wybuchowych (IED) na załogę pojazdów specjalnych, Wydawnictwo WAT, 2016.

4. Баум Ф.А., Станюкович К.П., Шехтер Б.И. Физика взрыва, Государственное издательство физико-математической литературы, 1959.

5. Chłopek Z. Synthesis of driving cycles in accordance with the criterion of similarity of frequency characteristics. Eksploatacja i Niezawodnosc Maintenance and Reliability, 2016; 18(4): 572-577.

6. Cytowicz N.A., Mechanika gruntów, Wydawnictwo Geologiczne, Warszawa, 1958.

7. Wiechuła B. M. The assessment of explosion risk in cabins during spraying coating powder, Eksploatacja i Niezawodnosc - Maintenance and Reliability, 2005; 1(25): 3-15.

8. Szturomski B. Modelowanie Oddziaływania Wybuchu Podwodnego na kadłub okrętu w ujęciu numerycznym, Wydawnictwo AMW, 2016.

9. MSC Dytran, Theory Manual, 2004.

10. STANAG 4569, Protection Levels for Occupants of Logistic and Light Armoured Vehicles, 24 May 2004. 